\title{
¿PUERTAS ABIERTAS? migrações regionais, direito e integração na Comunidade Andina de Nações e no Mercosul
}

\author{
José Sacchetta Ramos Mendes*
}

\begin{abstract}
O Mercosul e a Comunidade Andina de Nações estabeleceram, nas últimas décadas, legislações comunitárias sobre as migrações regionais e os migrantes. Os dois blocos foram instituídos a partir de metas de integração comercial e, posteriormente, agregaram temas sociais a seus objetivos. Este artigo apresenta o desenvolvimento normativo realizado nos processos sul-americanos de integração, em sua busca por soluções para a problemática dos deslocamentos humanos provindos de países vizinhos. Apesar dos avanços, subsistem obstáculos políticos e legais à regularização da condição dos migrantes e ao seu acesso a direitos sociais. Entre as razões apontadas, está o desalinhamento de normas internas dos países em relação aos acordos multilaterais e a pequena participação das sociedades sul-americanas na tomada de decisões. No artigo, comenta-se a adoção de princípios gerais fundamentados no respeito aos Direitos Humanos e a via de inclusão da migração e dos migrantes no projeto de uma cidadania regional.

Palavras-chave: Migração regional. América do Sul. Comunidade Andina de Nações. Mercosul.
\end{abstract}

\section{INTRODUÇÃO}

Quando Simon Bolívar conclamou a América do Sul à unidade política e territorial, em 1826, idealizava a supressão das fronteiras traçadas pelas metrópoles europeias. Uma decorrência desse ideal seria liberdade de trânsito e fixação dos cidadãos. Quase dois séculos depois, sem que a união tenha se concretizado, os sul-americanos continuam a vivenciar limites nos direitos de circular entre seus países e neles livremente se radicar. Os processos de integração regional que, nas últimas décadas, constituíram a Comunidade Andina de Nações (CAN) e do Mercado Comum do Sul (Mercosul) avançaram em diversos setores. Permanecem, porém, questões políticas e sociojurídicas que envolvem os trabalhadores migrantes e suas famílias. Em um continente onde diferenças nacionais são mitigadas no cotidiano, o desalinhamento de normas e procedimentos migratórios, o déficit participativo na tomada

* Universidade Federal da Bahia - UFBA. Instituto de Humanidades, Artes e Ciências Professor Milton Santos IHAC. Programa de Pós-Graduação em Direito.

Rua Barão de Jeremoabo s/n. Ondina. Cep: 40170-115. Salvador -Bahia-Brasil. josesacchetta@ufba.br de decisões e sua difícil implementação impõem obstáculos ao acesso a direitos sociais.

A análise dos dois processos de integração sul-americanos revela, entretanto, passos significativos em direção a uma governança migratória regional. Arcabouços legais adotados nos últimos anos e ações multilaterais ou localizadas buscam soluções para problemáticas da migração provinda de países vizinhos. A articulação entre Estados Partes da Comunidade Andina de Nações e do Mercosul, e, entre eles, os Estados Associados de cada um dos blocos, gera consequências no terreno das migrações regionais, ainda que nem sempre na velocidade e no sentido planejados.

Este texto aponta os principais desenvolvimentos nas legislações sobre migração e o trabalhador migrante adotadas na Comunidade Andina de Nações e no Mercosul. Criados em contextos distintos, os dois blocos sul-americanos guardam pontos de contato. Na gênese de ambos, um aspecto em comum foi a falta de atenção às migrações e ao trabalhador migrante fixado nos espaços comunitários. Nos textos legais constituintes, o Acordo de Cartagena (CAN, 1969) e o Tratado de Assunção (Merco- 
sul, 1994), a integração econômica e comercial era prioritária, a partir da qual se elencavam os objetivos institucionais a alcançar.

Contudo, se os tratados constitutivos não mencionaram as migrações e os migrantes, tais temas tomaram vulto nos debates setoriais. Na prática, eles foram assumidos como necessários à elaboração de estatutos consistentes acerca da circulação de bens, serviços e capitais. Era embrionária, na América do Sul, a noção de que o ato de imigrar, para além de um direito humano, deveria constar na prerrogativa da cidadania regional. As pressões dos movimentos sociais cumpriram papel importante nesse processo.

Na vocalização dos movimentos, a política para as migrações deve partir da adoção de normas que alicercem o livre deslocamento e a fixação das pessoas no espaço comunitário, bem como de medidas que equalizem regras de trabalho, previdência e acesso a direitos sociais. A integração regional adquire, desse prisma, perspectiva abrangente.

Os fluxos crescentes de trabalhadores entre os países sul-americanos, intensificados a partir de 1990, levaram à tomada de novas decisões em plano nacional e internacional. A ausência de coordenação, no que tange à adoção de diretrizes domésticas consoantes aos acordos regionais, e a reduzida centralização em matéria migratória são limites a superar. Os aparatos - legais instituídos pelo Mercosul e pela CAN, จे por sua vez, enfrentam restrições à efetiva aplicação no plano interno dos países, em grande i. parte devido a políticas públicas heterogêneas e desconexas, por vezes contrárias à expansão de direitos dos estrangeiros.

Entre as causas institucionais que dificultaram maior alcance e eficácia de ações conjuntas na esfera dos deslocamentos intrarregionais estão as mudanças ocorridas na configuração dos dois blocos sul-americanos, com adesão, retirada e suspensão de Estados Partes ao longo dos anos. As alterações incidem no processo de elaboração de diretrizes comuns e se mostraram mais acentuadas na Comunida- de Andina de Nações, com sua relativa instabilidade associativa. Exemplo disso foram os momentos de crise migratória entre Colômbia e Venezuela, em razão de obstáculos à regularização e mesmo à permanência, de grande número de trabalhadores colombianos radicados no país vizinho. A situação agravou-se em 2006, com a retirada de Caracas do bloco andino. Mesmo no Mercosul, onde o quadro associativo é mais estável, políticas relativas a migrantes de origem brasileira estabelecidos no Paraguai, brasiguaios, ressentiram-se da suspensão desse país do Mercosul, entre agosto de 2012 e janeiro de 2014.

O histórico de entradas e saídas de Estados Membros na CAN teve início com a formação do bloco regional pelos cinco países signatários do Acordo de Cartagena, cujos territórios, ao menos parcialmente, localizam-se na Cordilheira dos Andes: Bolívia, Chile, Colômbia, Equador e Peru. Até 1996, a CAN foi conhecida como Pacto Andino ou Grupo Andino. Em 1973, a Venezuela aderiu ao bloco. Em 1976, o Chile dele se retirou. Em 1993, o Peru foi suspenso, tendo sido readmitido no ano seguinte. Em 2006, a Venezuela deixou o grupo, o qual mantém, desde então, sua atual conformação, com quatro Estados Partes: Bolívia, Colômbia, Equador e Peru. A CAN tem também cinco Estados Associados, os quatro membros originários do Mercosul (Argentina, Brasil, Paraguai e Uruguai) e o Chile.

Os contingentes mais numerosos de migrantes regionais radicados nos países da Comunidade Andina de Nações, considerados os atuais e os ex-Estados Membros, são de colombianos no Equador e na Venezuela, venezuelanos na Colômbia e peruanos no Chile. As migrações bilaterais entre Colômbia e Venezuela constituem o principal fenômeno de deslocamento em massa na porção mais setentrional da América do Sul, nos últimos 50 anos. Apesar de ter origem nos tempos coloniais, as rotas de travessia entre os territórios que hoje formam os dois países foram fortalecidas a partir de 1970, na primeira fase 
de construção do Pacto Andino.

A violência rural na Colômbia, provocada pelo tráfico de drogas e pela ocupação de grandes extensões por grupos guerrilheiros, levou ao êxodo de mais de seiscentos mil trabalhadores em direção à Venezuela, país cujo crescimento econômico derivado da extração de petróleo atraiu imigrantes de muitas origens. A partir do ano 2000, a estabilização econômica, o combate ao narcotráfico e as negociações de paz entre o governo de Bogotá e a guerrilha das Forças Armadas Revolucionárias da Colômbia (FARC) fizeram reduzir a emigração de colombianos. Em sentido inverso, aumentou o ingresso de venezuelanos na Colômbia, sobretudo a partir de 2012, com o aprofundamento da crise econômica e institucional na Venezuela.

Ainda no âmbito das migrações internas na Comunidade Andina de Nações, há significativo movimento de peruanos que buscam trabalho no Chile. Novamente, o fenômeno remonta aos tempos coloniais e envolve a migração de bolivianos para a Argentina. Os deslocamentos populacionais nos Andes centrais são tão comuns às suas populações que as políticas da CAN devem ser negociadas com países que não integram o bloco, como a Argentina, destino de grande contingente de trabalhadores da região. O diálogo entre a CAN e seus Estados Associados é exigência prática no terreno das migrações regionais, em vista de sua abrangência extracomunitária.

O quadro associativo do Mercosul, por sua vez, com configuração mais estável, mantém seus quatro Estados Partes originários: Argentina, Brasil, Paraguai e Uruguai. A adesão da Venezuela, em 2013, ocorreu durante a suspensão do Paraguai após a deposição do presidente Fernando Lugo, considerada pelos governos dos outros países do bloco um desrespeito à democracia. $\mathrm{O}$ processo de adesão da Bolívia ao Mercosul, a partir de 2012, decorre do estreitamento da associação de La Paz ao conjunto mercosulino. Além da Bolívia, os Estados Associados ao Mercosul são Chile, Co- lômbia, Equador e Peru, os três últimos também integrantes da CAN.

A Argentina, como se disse, é o destino preferencial dos fluxos migratórios regionais no Mercosul. O caráter de receptor de imigrantes se inscreve historicamente no ordenamento jurídico argentino. O país abriga grande coletividade de paraguaios, bolivianos, chilenos, peruanos e uruguaios, o que o torna uma intersecção de fluxo migratório entre as duas organizações sub-regionais: a Comunidade Andina de Nações e o Mercosul. O Paraguai tem, na sua população, contingentes elevados de migrantes brasileiros e argentinos. Os brasileiros e seus descendentes fixados no Paraguai constituem o principal fenômeno de emigração brasileira na América do Sul.

O deslocamento em massa de brasileiros para o Paraguai teve início durante a construção da Usina Hidrelétrica de Itaipu (19751982), que inundou larga extensão territorial do Estado do Paraná com densidade demográfica considerável. A baixa indenização levou pequenos proprietários a optar pela compra de lotes no Paraguai, em um movimento facilitado pela nova Lei de Terras daquele país (1967), que promoveu o assentamento de lavradores estrangeiros (Estrada, 2015). A legislação atraiu também latifundiários brasileiros, que estimularam a ida de trabalhadores sem terras para o país vizinho. O Brasil, por sua vez, viu crescer, nas últimas duas décadas, a migração de bolivianos para o Estado de São Paulo, além da continuidade de correntes nacionais de menor porte: argentinos, paraguaios, uruguaios e chilenos.

\section{O DEBATE SOBRE MOBILIDADE INTERNA NA COMUNIDADE ANDINA DE NAÇÕES}

A preocupação política com questões migratórias regionais foi levada ao plano dos dispositivos normatizadores da CAN Comunidade Andina de Nações após duas décadas de 
existência do bloco. Em 1990, a Ata de La Paz assumiu, em sua Diretriz Presidencial $n^{\circ} 7$, o objetivo de suprimir a exigência de visto de entrada para nacionais dos países membros da Comunidade Andina de Nações (CAN, 2015) O documento tornou-se um marco orientador para as políticas migratórias comunitárias na região da Cordilheira dos Andes. A meta de aprofundar a integração andina buscava agregar temas sociais, com previsão de se iniciarem programas em prol do desenvolvimento de uma seguridade social regionalizada. A Diretriz Presidencial $n^{0} 7$ da Ata de La Paz tem o seguinte texto:

Com o propósito de superar barreiras para o trânsito fluido dos nacionais da sub-região (Andina), (os membros da CAN) acordam em eliminar, em um prazo não maior de seis meses, o requisito de vistos aos nacionais dos Países Membros para permanências de até noventa dias. Nesse sentido, acordam em promover o estabelecimento de um sistema andino de informação e controle de migração que facilite o trânsito e a permanência dos cidadãos andinos na sub-região (Id., ibid.).

A Ata de La Paz, suas diretrizes e as disposições constantes em seus anexos redefiniram o desenho institucional da Comunidade Andina de Nações. Assinado pelos cinco Estados Partes (a Venezuela, à época, integrava o bloco), o documento avançou na tentativa de estabelecer uma estrutura democrática. Sua Diretriz Presidencial no 10 previa participação empresarial e laboral na elaboração das políकิ ticas gerais, abrangendo a área social e, nela, $\hat{A}$ presumivelmente, os temas migratórios.

A instância de participação dos empresários, definida na Ata de La Paz, é a Confe\& deração dos Empresários Privados Andinos, o entidade que nunca funcionou de fato. As $>$ associações empresariais dos Estados Partes da CAN não têm um organismo plurinacional 胥 que as unifique. De outra parte, o documento sequer indicou instância participativa dos trabalhadores no processo de integração. Sem a presença de representantes legítimos de empresários e trabalhadores nas negociações, a
Ata de La Paz indicou que "o Conselho Andino de Ministros das Relações Exteriores definirá as modalidades para a participação dos setores empresarial e laboral" (Id. ibid.).

Não obstante o déficit participativo, nos três anos seguintes à assinatura da Ata de La Paz, sucessivas reuniões de colaboração entre autoridades migratórias levaram à formação, em 1993, do Comitê Andino de Autoridades de Migração (CAAM). O Comitê constituiu-se com delegados dos Ministérios das Relações Exteriores dos países participantes. O caráter meramente propositivo de suas conclusões técnicas fez com que elas dependessem de aceitação dos agentes detentores da prerrogativa de deliberação, tanto na esfera do Executivo quanto do Legislativo dos Estados Partes da CAN.

Entre as funções iniciais designadas ao Comitê Andino de Autoridades de Migração estava a de harmonizar as legislações migratórias dos Estados Partes por meio de negociações coordenadas pela Secretaria Geral da Comunidade Andina. Do ponto de vista imediato, após a sua criação, a tarefa do Comitê foi fixar regras para os Países Membros reconhecerem reciprocamente os documentos de identidade de seus nacionais. O primeiro instrumento de política migratória criado para facilitar a circulação de pessoas na área intrabloco da CAN foi o Cartão Andino de Migração (Tarjeta Andina de Migración, conhecida por TAM). Sua criação havia sido recomendada pelo Comitê Andino de Autoridades de Migração, em conjunto com o Comitê Andino de Turismo.

A Decisão ${ }^{\circ} 397$ que criou a Tarjeta Andina de Migración em 1996, determinou que o documento "constitui o único instrumento de controle migratório e estatístico de uso obrigatório para o ingresso e saída de pessoas do território dos Países Membros”. A mesma norma determinou que o uso do cartão "não exclui a apresentação de passaporte, visto ou outro documento de viagem, previstos nas normas nacionais ou comunitárias, assim como nos convênios bilaterais vigentes" (CAN, 1996, p. 
6). Ainda que muitos migrantes regionais não tenham inicialmente se cadastrado junto às autoridades, a criação da Tarjeta Andina de Migración possibilitou crescentemente o controle e a quantificação de pessoas em trânsito na região andina. Abriu, assim, nova etapa na organização de um sistema integrado de dados estatísticos migratórios.

Em 2001, após cinco anos de funcionamento da Tarjeta Andina de Migración, um conjunto de Decisões comunitárias aprofundou a meta de governança migratória na Comunidade Andina de Nações. Assinale-se que o ordenamento do bloco regional andino é constituído por normas supranacionais denominadas Decisões (Decisiones), que são revestidas de caráter obrigatório, prevalente, diretamente aplicável e gerador de efeitos legais imediatos no território dos Estados Partes da CAN.

Assim, por meio da Decisão ${ }^{\circ} 501$, de 22/01/2001, o Conselho de Ministros das Relações Exteriores da CAN instituiu Zonas de Integração Fronteiriça (ZIF), visando a "impulsionar o desenvolvimento sustentável e a integração de fronteiras de maneira conjunta, compartilhada, coordenada e orientada a obter benefícios mútuos” (Id., 2001, p. 9). Há séculos, os deslocamentos humanos na Cordilheira dos Andes fazem uso de caminhos definidos pela geografia montanhosa. A experiência colonial e, mais recentemente, a formação dos modernos Estados sul-americanos traçaram divisas que separam grupos populacionais de notável homogeneidade cultural e linguística. Isso se verifica em maior grau no Altiplano, área extensa de planalto que abrange o sul do Peru, o oeste da Bolívia, o nordeste do Chile e o noroeste da Argentina (onde é denominado Puna).

A Organização Internacional das Migrações (OIM) menciona, em seu Panorama Migratorio de America del Sur 2012, a ocorrência de "contínuos fluxos migratórios nas zonas fronteiriças de Equador e Peru, Colômbia e Equador, Bolívia e Peru, onde milhares de pessoas trasladam-se continuamente de um país a outro com fins laborais, familiares e de outro tipo" (OIM, 2012, p. 90). Na dimensão integradora da CAN, esse trânsito cotidiano de pessoas impõe a simplificação dos procedimentos migratórios nas zonas de fronteira.

Na mesma data de criação das Zonas de Integração Fronteiriça (ZIF), de maneira complementar, a Decisão n 502 da Comunidade Andina de Nações determinou a implantação de Centros Binacionais de Atenção nas fronteiras entre Países Membros, para aprimorar o controle da passagem de pessoas, evitar duplicidade de trâmites e de registros de entrada e saída, aspectos que o Cartão Andino de Migração não havia sido capaz de solucionar. Avançando no processo, as carteiras de identidade emitidas em âmbito doméstico pelos países da CAN passaram a valer como documento de viagem para turistas e viajantes de curta estadia no interior do bloco (CAN, 2001 p. 13-20).

Ainda em 2001, a Decisão n 504 criou um documento unificado para viagem internacional denominado Passaporte Andino (Id., 2001, p. 49), a exemplo do Passaporte Mercosul, instituído pouco antes, como modelo a ser utilizado pelos cidadãos em deslocamentos extracomunitários. Para além de ser um documento identificador, o texto legal informava que o Passaporte Andino deve se constituir em instrumento para coadjuvar a "consolidação de uma consciência e uma coesão comunitária entre os nacionais dos Países Membros e à identificação internacional da Comunidade Andina como conjunto de países comprometidos com um projeto integrador comum” (Id., ibid.).

A emissão e o uso do Passaporte Andino entraram em vigor na Bolívia, no Equador e no Peru a partir de 2006 e, na Colômbia, após 2010. A Venezuela, que havia participado da concepção do passaporte comunitário - a Decisão ${ }^{0} 504$ foi firmada em ato multilateral na cidade venezuelana de Valência -, embora tenha iniciado a implantação do documento, abandonou o seu uso após retirar-se do bloco regional.

Um aspecto da instituição do Passaporte Andino foi constituída das medidas visando a ampliar a assistência consular e a proteção in- 
ternacional extracomunitária a migrantes dos Estados Partes. A Decisão n 548 de 25/06/2003, do Conselho Andino de Ministros das Relações Exteriores, determinou que os portadores do documento de viagem unificado possuíssem prerrogativa de proteção de agentes estatais de qualquer um dos Estados Membros da CAN, nos casos em que seu país de origem não tivesse representação diplomática ou consular na localidade onde ela se fizesse necessária. As situações relacionadas aos migrantes andinos fora do espaço comunitário, previstas na Decisão ${ }^{\circ}$ 548, abrangem indigência, catástrofes naturais, estado de guerra, tráfico de pessoas, prostituição, crimes internacionais, exercício do direito de defesa judicial etc. (Id., 2003, p. 50).

A Decisão $\mathrm{n}^{\circ} 548$ renovou e ampliou o mecanismo diplomático de cooperação consular em terceiros países, adotado em 1911 no Acordo sobre Cônsules firmado por Bolívia, Colômbia, Equador, Peru e Venezuela. Naquele instrumento, décadas antes da constituição da CAN, os países que viriam a constituí-la previram uma política conjunta de proteção a seus nacionais fora do espaço andino. Apesar do fio condutor, foi apenas com as Decisões aprovadas em 2001 que teve início um ordenamento migratório na CAN. A ênfase normativa dos primeiros anos do século XXI, centrada em documentos de viagem e identificação de pessoas em trânsito, reforçou noções de segurança das fronteiras internas do bloco andino. AmpliaN ram-se o controle e a vigilância sobre os desSิ locamentos, com informatização de dados e unificação de procedimentos.

8ิ Não obstante o período ter sido marcado mundialmente pelo endurecimento das normas \& de segurança de viagem, cabe lembrar que os o dispositivos em tela foram aprovados pela Comunidade Andina de Nações em junho de 2001, antes dos episódios de 11 de setembro nos EUA. No que tange à governança migratória participativa, assinale-se, uma vez mais, o déficit de consulta a representantes de trabalhadores e outros seguimentos das sociedades andinas nos processos de adoção das Decisões $n^{0} 501, n^{\circ}$
$502, n^{0} 503$ e $n^{0} 504$, portadoras de implicações legais para os migrantes intrarregionais.

\section{TRABALHO E SEGURIDADE SO- CIAL: a normatização das migra- ções laborais na CAN}

O desenvolvimento da legislação do trabalho migrante no espaço andino se expressou na aprovação de três documentos normativos diretamente relacionados às migrações permanentes ou de longa duração. São enunciados que definem os deslocamentos humanos como parte das relações de trabalho em escala sul -americana. O primeiro texto legal desse rol, a Decisão $n^{0} 545$, de 25/06/2003 (relembrando que as Decisões da CAN têm força de lei), criou o Instrumento Andino de Migração Laboral, com regras para facilitar a circulação e a fixação de nacionais dos países do bloco com fins de trabalho. Seu artigo $4^{\circ}$ define trabalhador migrante andino (o nacional de um País Membro que se traslada a outro País Membro com fins laborais sob relação de dependência, seja de modo temporário ou permanente) e o classifica em quatro tipos: a) trabalhador que se desloca individualmente, b) trabalhador de empresa, c) trabalhador temporário e d) trabalhador fronteiriço. (Id., 2003, p. 23-29)

$\mathrm{O}$ enquadramento do trabalhador migrante em grupos distintos tem o objetivo de promover seu acesso e o de seus dependentes a prerrogativas legais, conforme os documentos que o fundamentaram. Na prática, a diferenciação tem provocado o efeito contrário de restringir o exercício de direitos. Isso se agrava com o emprego dos tipos previstos nas Disposições Transitórias da Decisão ${ }^{0} 545$ por parte de autoridades migratórias e policiais, sem que tenha sido aprovado um regulamento que oriente a aplicabilidade comum da norma. As categorias de trabalhador migrante permanecem, assim, vinculadas às legislações internas e não a uma norma comunitária.

Sem regulamentação, o Instrumento 
Andino de Migração Laboral permanece com eficácia prejudicada. Colômbia, Equador e Peru adotaram normativas regulamentadoras próprias, relativas à Decisão no 545 que, porém, não têm vigência comunitária. Elas sequer garantem compromissos fundamentais assumidos, entre eles o previsto no Artigo 20 ${ }^{\circ}$, que estabelece como princípio ordenador "reconhecer a liberdade de circulação dos trabalhadores migrantes andinos [...] e não adotar novas medidas que restrinjam o direito à livre circulação e permanência para os trabalhadores migrantes" (Id., ibid).

O segundo dispositivo legal instituído para facilitar as migrações laborais no espaço comunitário da CAN foi o Instrumento Andino de Seguridade Social, criado por meio da Decisão $n^{\circ}$ 583, de 07/05/2004. Seu objetivo é garantir a adequada proteção social dos trabalhadores migrantes e seus beneficiários para que, em consequência da migração, não sejam diminuídos os seus direitos sociais (Id., 2004, p. 30-36). Aqui, o princípio definidor é a igualdade de tratamento e acesso a direitos sociais entre nacionais dos Países Membros da CAN. O Instrumento Andino de Seguridade Social também não foi regulamentado em âmbito comunitário. A formação de um Comitê Andino de Autoridades de Seguridade Social não foi suficiente para levar o conjunto do bloco regional a adotar uma regulamentação que permita a entrada da norma em vigor.

O terceiro dispositivo legal diretamente relacionado aos trabalhadores migrantes é o Instrumento Andino de Seguridade e Saúde no Trabalho, criado por meio da Decisão n ${ }^{0} 584$, de 07/05/2004. Seu objetivo é a harmonização gradual das políticas econômicas e sociais e a aproximação das legislações nacionais dos Países Membros nas matérias pertinentes (Id., 2004, p. 37-46) Seguridade e saúde no trabalho são elevadas à condição de prioridade social. No conjunto de Decisões que visam a facilitar a imigração laboral no espaço comunitário da CAN, esse instrumento teve um processo de institucionalização mais célere, tendo sido regulamentado pela Resolução $\mathrm{n}^{\circ}$ 957, de 23/09/2005, o que possibilitou sua entrada em vigor e consequente geração de efeitos sociais.

A harmonização de legislações nacionais, prevista no Instrumento Andino de Seguridade e Saúde no Trabalho, abrange o aperfeiçoamento dos sistemas domésticos mediante ações que propugnem políticas de prevenção, com participação do Estado e da sociedade. No atual estágio de estruturação da Comunidade Andina de Nações, levando em conta a dificuldade de representação plurinacional, é notável o envolvimento de centrais sindicais, associações nacionais de empregadores e organizações locais nas tomadas de decisão. Desde que o Instrumento entrou em vigência, os Países Membros incorporaram diretivas da norma supranacional, transformada em condutora de difusão e acesso a direitos sociais. Nesse caso, a adoção de uma norma legal comum é o melhor exemplo da possibilidade de avanço na governança migratória na região andina.

\section{A FORMAÇÃO DO MERCOSUL E A EMERGÊNCIA DAS MIGRAÇÕES REGIONAIS}

O projeto de construção do Mercado Comum do Sul também teve origem em pressupostos de integração econômica. A perspectiva social foi incorporada ao bloco comunitário em um segundo momento. A exemplo dos Andes, a região é terreno de migrações históricas. Desde o período pré-colonial, os deslocamentos ocorrem nas bacias fluviais do Amazonas e do Prata. As fronteiras dos modernos Estados do Cone Sul consolidaram divisões nacionais. Polo de atração de imigrantes de outros continentes, os países do Mercosul, durante certo tempo, deram menor atenção aos fluxos regionais. Até recentemente, as legislações não diferenciavam a entrada e a fixação de trabalhadores intrabloco das normas para migrantes extracomunitários.

O tema da migração regional e as 
questões dos migrantes ficaram de fora do Tratado de Assunção. O documento fundador do bloco não incluiu aspectos sociais, centrando-se no livre comércio e circulação de bens, serviços e outros fatores produtivos. O texto tampouco relacionou fatores de impacto social, como migrações, com seus objetivos econômicos. A omissão pode ser compreendida no contexto de fortalecimento de plataformas econômicas neoliberais pelos governos signatários do pacto do Mercosul, no início da década de 1990, com suas políticas de abertura comercial e flexibilização de direitos trabalhistas, em ambiente de globalização (Hirst, 1995, p. 174).

O enfoque do Tratado de Assunção, circunscrito a metas de comércio, foi uma das críticas mais frequentes à concepção de origem do Mercosul. O Anexo ao Tratado, que esboçou o desenho institucional do bloco, previu, em seu Artigo $5^{\circ}$, a formação, na estrutura organizativa, de dez subgrupos de trabalho dedicados ao processo de integração. Nenhum deles vinculava-se a questões sociais. Outra observação crítica à primeira fase do processo comunitário relacionava-se à ausência de um órgão ou mecanismo voltado para a redução de assimetrias e disparidades de desenvolvimento humano entre os países do bloco e regiões internas de cada um deles.

A respeito disso, o Fundo de Convergência Estrutural do Mercosul (Focem) foi criado em 2004 e passou a funcionar em 2006, tendo como . prioridade o combate a assimetrias para ampliar S. a competitividade entre os países. A questão mi¿ gratória e laboral, compreendida como fator de के desigualdade, foi inserida no objetivo genérico 될 de coesão social e redução da pobreza, sem mena ção direta no escopo do Focem e da destinação ờ de seus recursos. Após o primeiro quinquênio $\therefore$ de funcionamento, o Focem passou a enfrentar dificuldades para operar, devido à interrupção, a partir de 2013, do aporte de recursos devidos fi pelo Brasil, seu principal contribuinte.

Ainda na primeira fase do Mercosul, seu núcleo executivo, coordenado pelos Ministérios do Exterior (Grupo Mercado Comum
- GMC), abriu o debate sobre a circulação de cidadãos no espaço comunitário, em parte devido aos protestos da Coordenadoria das Centrais Sindicais do Cone Sul. Em 1991, o GMC instituiu o Subgrupo de Trabalho $\mathrm{N}^{\mathrm{O}}$ 11 - Assuntos Trabalhistas, renomeado no ano seguinte Subgrupo para Relações Trabalhistas, Emprego e Seguridade Social. A nova nomenclatura expressava a maior abrangência do seu mandato, que passou a abarcar dois focos de atenção: 1) problemas relativos um rol de direitos trabalhistas e previdenciários previstos na ordem doméstica daqueles Estados por cidadãos do Mercosul residentes em outro Estado Parte; 2) dificuldades legais para fixação e inserção de trabalhadores dos Estados Partes no mercado laboral dos outros países do bloco. O Subgrupo de Trabalho (SGT) $\mathrm{n}^{0} 11$ visava a atuar sobre questões práticas que envolvem trabalhadores migrantes e residentes estrangeiros originários dos Estados Partes, atendo-se às regras do país de acolhimento. Seu objetivo nunca foi contribuir para uma legislação unificada sobre temas de migração e laborais. Essa limitação não proporcionou que se constituíssem mecanismos e políticas comuns. Mesmo assim, algumas soluções de âmbito bilateral e mesmo multilateral puderam emergir.

Importa sublinhar a falta de um plano de ordenamento comunitário para as migrações na formação do Mercosul. Propostas de estabelecer normas unificadas para o trânsito de cidadãos partiam da perspectiva de integrar mercados, levando em conta, subsidiariamente, o fator laboral. A ausência de projeto político para questões sociais foi marcante na adoção das primeiras medidas relacionadas ao deslocamento dos cidadãos no espaço do Mercosul, ainda que demandas por reconhecimento e inclusão desses fatores estivessem presentes, na ação dos sindicatos, já no início da década de 1990.

O Brasil, membro mais populoso e detentor da maior economia do Mercosul, experimentava, à época, uma reorganização de 
suas instituições, como resultado da nova Constituição Federal de 1988. Exemplo disso, na esfera internacional, foi a abertura do Itamaraty à participação de organizações da sociedade civil (inclusive centrais sindicais), na formulação de sua política externa ambiental, já nos governos de Itamar Franco (1992/1994) e Fernando Henrique Cardoso (1995/2002). Situação diversa atravessou a Argentina nos primeiros anos do Mercosul, quando a austeridade econômica e a flexibilização de leis trabalhistas conduzidas pelo governo de Carlos Menem (1989/1999) não favoreceram maior participação em temas internacionais.

\section{A ADOÇÃO DO CONCEITO DE MI- GRAÇẪO LABORAL NO MERCOSUL}

A assinatura do Protocolo de Ouro Preto, em dezembro de 1994, modificou a estrutura orgânica do Mercosul, redefiniu e ampliou seus objetivos. A mudança se refletiu em maior atenção a questões migratórias. Entre os órgãos criados, havia o Foro Consultivo Econômico-Social, um espaço institucional que buscava, ao menos nas metas oficiais, atender à demanda participativa de setores das sociedades dos países do bloco. ${ }^{1}$ Apesar de o órgão não possuir poder de deliberação, foi nos debates ocorridos no Fórum Consultivo Econômico-Social que a questão da mobilidade de cidadãos, no espaço territorial do Mercosul, mudou seu enfoque, novamente devido à intervenção de movimentos sociais e representantes de centrais sindicais.

Foi também no âmbito do Foro Consultivo Econômico-Social que se descartou o plano para assinatura de um acordo simplificado sobre livre circulação de pessoas, proposto por economistas brasileiros e argentinos, com viés voltado ao fornecimento de mão de obra. Inversamente àquela proposta, assumiu-se o concei-

1 MERCOSUL. Protocolo de Ouro Preto Adicional ao Tratado de Assunçấo, de 17/12/1994. Disponível em: http://www.mercosur.int/msweb/portal\%20intermediario/Normas/Tratado\%20e\%20Protocolos/Ouro\%20Preto_ PT.pdf. Acesso em: 27 nov. 2014. to de imigração laboral como norteador do debate sobre os movimentos humanos regionais no Mercosul. A mudança conceitual apontou para a necessidade de um estatuto jurídico comunitário capaz de responder às diversas questões sobre mobilidade internacional, fixação de mão de obra e exercício de direitos por cidadãos residentes noutros países do bloco.

O regime de administração integrada do trânsito de nacionais em fronteiras, estabelecido nos primeiros anos do Mercosul, deveria dar lugar a um sistema geral de cooperação em assuntos migratórios, definição e regulamentação de um conjunto de demandas. Entre elas, constavam tópicos sobre residência temporária e permanente, direitos trabalhistas, previdenciários e acesso a benefícios sociais (saúde, educação etc.) em igualdade de condições com os nacionais dos países de acolhimento (Geneyro et al., 1998, p. 193-204). No Foro Consultivo Econômico-Social, o diálogo institucional do Mercosul passou a se referir a uma acepção de cidadania comunitária. Contudo, a definição e a abrangência da cidadania do Mercosul apresentavam-se como questões abertas, não discutidas em esfera oficial, e assim permaneceram até dezembro de 2010, quando os quatro Estados Partes estabeleceram um plano de ação multilateral com aquele intuito.

Na segunda metade da década de 1990, durante o processo de reestruturação dos órgãos do Mercosul em decorrência do Protocolo de Ouro Preto, cresceu a pressão de centrais sindicais e movimentos sociais, no Brasil e na Argentina, para encaminhamento de demandas sobre emprego de mão de obra estrangeira. As reivindicações evocavam normativas editadas pela Organização Internacional do Trabalho (OIT) e pela Associação Internacional de Seguridade Social. A pressão sindical contou com apoio de partidos políticos e organizações não governamentais. Em 17 de dezembro de 1996, os grupos envolvidos no debate promoveram um Dia Internacional de Luta pelos Direitos dos Trabalhadores do Mercosul, com manifestações nos quatro países e lançamento 
de um documento que defendia a unificação de leis trabalhistas e previdenciárias, além de maior agilidade na implementação de medidas relativas aos trabalhadores estrangeiros (Soares Filho, 2009, p. 21-38).

\section{DOIS APORTES NA LEGISLAÇÃO SOCIAL DO MERCOSUL}

No lastro político da ampliação de objetivos do Mercosul, determinada pelo Protocolo de Ouro Preto, consolidou-se a ideia de elaborar instrumentos para promover o desenvolvimento humano no contexto comunitário. Apesar da oposição inicial do governo argentino, depois alterada, firmaram-se dois importantes aportes normativos: o Acordo Multilateral de Seguridade Social, de dezembro de 1997, e a Declaração Sociolaboral do Mercosul, de dezembro de 1998. Ambos os mecanismos incidem nas questões da migração intrarregional, dos trabalhadores migrantes e suas famílias.

O Acordo Multilateral de Seguridade Social, marco da proteção previdenciária no Mercosul, objetivou garantir o exercício de direitos aos trabalhadores migrantes, nacionais dos Estados Membros e de Estados Associados. Foi o primeiro documento a conferir direitos sociais ao conjunto dos residentes do bloco, em particular direitos previdenciários - relativos à saúde do trabalhador e de seus deง pendentes. Por seu intermédio, os signatários concordaram em outorgar aos cidadãos comuN ¿ nitários e associados - além de trabalhadores \& estrangeiros provindos de terceiros países - os 될 mesmos direitos e obrigações devidos a seus $\therefore$ nacionais. Obrigaram-se, desse modo, a recoi nhecer aos migrantes os benefícios previdenciários estabelecidos em sua legislação interna.

O documento não implicou modificação das normas domésticas dos Estados, cumprindo a cada um deles analisar os pedidos individuais de benefícios, definir condições de reconhecimento e aplicabilidade. Nessa perspectiva, o Acordo Multilateral de Seguridade Social do Mercosul, em seu Título II, Artigo $2^{\circ}$, inciso 1, especificou a abrangência dos destinatários aos quais deve ser aplicado:

Os direitos à seguridade social serão reconhecidos
aos trabalhadores que prestem ou tenham prestado
serviços em quaisquer dos Estados Partes, sendo-
lhes reconhecidos, assim como a seus familiares e
assemelhados, os mesmos direitos e estando sujei-
tos às mesmas obrigações que os nacionais de tais
Estados Partes com respeito aos especificamente
mencionados no presente Acordo. ${ }^{2}$

No mesmo Artigo $2^{\circ}$, inciso 2, o documento ampliou sua abrangência para os trabalhadores extracomunitários. A adoção desses dispositivos configurou o reconhecimento da igualdade de direitos trabalhistas e previdenciários entre nacionais e estrangeiros, ainda que o rol de direitos seja distinto em cada país, já que se refere a normas internas. A importância desse reconhecimento não impediu que o processo de ratificação do Acordo se arrastasse por oito anos. No Brasil, a aprovação se deu em 2001. O último país a ratificá-lo foi o Paraguai, em 2005.

O Acordo Multilateral de Seguridade Social atua como base jurídica para extensão e garantia de direitos sociais, além de conter diretrizes de respeito aos direitos humanos e favorecimento legal aos trabalhadores cidadãos do Mercosul. Por essas razões, o documento é um balizador da interação entre os sistemas de proteção social da região (COSTA et al., 2010, p. 205-229). O Acordo incide sobre um quadro diversificado de direitos e normas reguladoras internas aos países, nem sempre com correspondência internacional. Acerca disso, é preciso observar que a conexão entre sistemas nacionais não projetou uma política previdenciária comum aos Estados Partes do Mercosul.

Em novembro de 1997, um mês antes da assinatura do Acordo Multilateral de Seguridade Social, criou-se a Comissão Ad Hoc

2 Acordo Multilateral de Seguridade Social do Mercosul, de 15/12/1997, promulgado pelo Decreto $\mathrm{n}^{\circ} 5.722$, de 13/03/2006. Disponível em: http://www.planalto.gov.br/ ccivil_03/Ato2004-2006/2006/Decreto/D5722.htm. Acesso em: 12 dez. 2014 . 
sobre a Dimensão Social do Mercosul. Com estrutura tripartite, formada por representantes dos governos, de empresários e trabalhadores, a comissão elaborou um projeto de Carta Social. Um ano depois, a proposta foi aprovada no Conselho Mercado Comum, que a denominou Declaração Sociolaboral do Mercosul (DSL).3 Festejada como um avanço, em termos de estrutura jurídica voltada para proteção e garantia dos direitos sociais no bloco regional, a legislação deixou de fora algumas das principais reivindicações dos trabalhadores, que não foram aceitas pelos representantes dos governos e dos empresários na comissão tripartite.

A busca por consenso mínimo na Comissão $A d$ Hoc sobre a Dimensão Social do Mercosul foi compreendida pelos trabalhadores, naquele momento, como suficiente e prioritária para viabilizar a Declaração Sociolaboral. Havia perspectiva de revisar a DSL a partir de 1999, o que não ocorreu. Em 2003 e 2004, houve nova tentativa de reabertura, sem sucesso, da discussão para ampliar a DSL. Entre os pontos defendidos pelas centrais sindicais e retirados do texto mínimo aprovado em 1998, estavam a definição da natureza jurídica do trabalho e as atribuições da Comissão de Seguimento da Declaração Sociolaboral, responsável por acompanhar a aplicação do acordo.

A adoção pelo Mercosul de princípios na área trabalhista, desde então incorporados ao processo de integração regional, é elemento definidor da Declaração Sociolaboral. O documento agregou pontos programáticos de caráter social à construção do bloco, figurando como complemento normativo ao Tratado de Assunção e ao Protocolo de Ouro Preto. Nesse nível, sua potência no ordenamento das migrações torna-se determinante. Já no Preâmbulo, a DSL afirmou adesão integral à Declaração da Organização Internacional do Trabalho (OIT) relativa à defesa dos direitos humanos e dos direitos dos trabalhadores, inclusive circula-

${ }^{3}$ PEDUZZI, M. C. I. "Aplicabilidade da Declaração Sociolaboral do Mercosul nos Estados Partes". In: STF.jus. Palestra. s/d. Disponível em: ht p://www.stf.jus.br/imprensa/ pdf/peduzzi.pdf. Acesso em: 19 fev. 2015. ção de força de trabalho. A Declaração da OIT foi firmada na Filadélfia (EUA), em junho de 1998, durante o funcionamento da Comissão Ad Hoc, que redigiu a proposta de Carta social e a tomou em referência.

A Declaração Sociolaboral do Mercosul assegura aos trabalhadores igualdade de oportunidades e de tratamento no emprego e ocupação. O princípio de não discriminação inscreve-se em seu Artigo $1^{\circ}$ e assenta bases para a igualdade de direitos entre os cidadãos do bloco em um futuro mercado laboral comum. Mas o debate sobre imigração e livre trânsito de trabalhadores no espaço comunitário sofreu vários obstáculos na Comissão Ad Hoc sobre a Dimensão Social, na qual pouco se avançou. A única temática sobre migração que obteve relativo consenso na comissão tripartite e pôde ser satisfatoriamente normatizada foi a situação dos trabalhadores de fronteira.

A resolução dos problemas desse grupo era, então, considerada urgente. Uma característica dos trabalhadores de fronteira é a alta mobilidade, aspecto que potencializa riscos e dificulta acesso a benefícios. Daí a premência de sua normatização. A importância da medida ressalta sua implementação incompleta. A falta de consenso sobre demandas das centrais sindicais impôs limites à aplicação da Declaração Sociolaboral, devido, uma vez mais, a imposições internas aos Estados. Nesse caso, não se pode, contudo, atribuir as dificuldades à ação de governos e de representantes patronais. O princípio da não discriminação no trabalho, por exemplo, deve sua contenção à defesa de interesses setoriais, reservas corporativas e exigências de conselhos profissionais articulados nacionalmente, pretensamente para proteger seu mercado laboral.

$\mathrm{O}$ argumento da defesa dos mercados nacionais de trabalho apresenta-se como um obstáculo à isonomia de oportunidades para trabalhadores migrantes regionais. Isso foi identificado já na Conferência Regional sobre Migrações, celebrada em Puebla, no México, em 1996, com o objetivo de levantar questões 
migratórias e constituir um foro continental sobre migrações. Ainda que a meta de um foro das Américas não tenha sido alcançada, o encontro teve como desdobramento a abertura de um processo de concertação, em matéria migratória, entre os doze países da América do Sul. Tal processo se expressou na realização, em 1999, da Conferência Sul-Americana sobre Migrações, que, desde então, se reúne periodicamente em busca de promover políticas garantidoras dos direitos humanos, sociais e trabalhistas dos migrantes regionais.

\section{OS ACORDOS PARA REGULARIZAR A MIGRAÇÃO REGIONAL NO MER- COSUL}

A partir de 2002, o Mercosul criou diversos instrumentos para facilitar a permanência e a circulação de trabalhadores migrantes originários de outros países do bloco dentro do espaço comunitário. Durante a XII Reunião dos Ministros do Interior, em Salvador, Bahia, foram assinados o Acordo sobre Regularização Migratória Interna do Mercosul e o Acordo sobre Regularização Migratória do Mercosul, Bolívia e Chile (Acordos no 11/02 e no 12/02). O encontro firmou um terceiro convênio, dedicado às migrações intrarregionais: o Acordo de Livre Transito e Residência para Nacionais dos E. Estados Partes do Mercosul (Acordo n ${ }^{0}$ 13/02). ลे Ainda em 2002, foi assinado, em Brasília, o Acordo de Livre Trânsito e Residência $\therefore$ para Nacionais dos Estados Partes do Mercoơ sul, Bolívia e Chile (Acordo $n^{\circ}$ 14/02). É quan될 do se constituiu, pela primeira vez na América a do Sul, uma Área de Livre Residência, com oे direito de acesso ao trabalho a nacionais dos

Estados signatários, sem exigência de outro requisito além da nacionalidade. Na prática, a acepção de uma cidadania comunitária mercosulina avançou na área dos direitos de migração e trabalho.

No conjunto, as quatro convenções de 2002 reconheceram direitos nas esferas civil e trabalhista aos nacionais dos Estados Partes e Associados ao Mercosul que residam ou trabalhem em outro país do bloco. Garantiram também a esses migrantes a prerrogativa de acesso a toda atividade laboral nas mesmas condições que os nacionais do país de acolhimento. Por tais características, os Acordos de 2002 foram considerados pela Organização Internacional para as Migrações "verdadeiro feito na história da integração regional, por darem sustento à governabilidade dos fluxos migratórios, entendendo que a legalidade constitui a base de toda sociedade democrática e que permite a inserção dos imigrantes na sociedade receptora" (OIM, 2012, p. 90). ${ }^{4}$ A ênfase positiva deve ser compreendida em meio a dificuldades de implementação dos Acordos de 2002 nos Estados Membros do Mercosul, com exceção da Argentina.

Os Acordos de 2002 foram compromissos assumidos para com a regularização do livre trânsito, da residência e das relações de trabalho de nacionais do Mercosul e de seus Associados no espaço comunitário em formação. No Brasil, a permissão de residência provisória dá ao migrante mercosulino o direito de solicitar Carteira de Trabalho e Previdência Social, mediante simples demonstração documental da nacionalidade. Tanto a autorização provisória para residir como para trabalhar ou abrir empresa deve ser renovada após dois anos, quando poderá se tornar permanente. Nesse ponto surgem entraves, pois os requisitos para renovar a autorização são mais rigorosos que as condições simplificadas para obter a primeira permissão.

Quanto à edição de normas e procedimentos relativos à migração após os Acordos de 2002, verificou-se contínua disparidade de desenvolvimento entre os países. Assim, enquanto a Argentina adotou, em 2004, uma nova lei de imigração e, em 2006, implantou o Plano Pátria Grande, estabelecendo legislação ${ }^{4}$ ORGANIZAČ̃̃ INTERNACIONAL PARA AS MIGRAÇÕES (OIM). Panorama Migratorio de América del Sur 2012. Buenos Aires: OIM, Oficina Regional para a América del Sul, 2012, pp. 98-99. 
que incorpora as determinações do Mercosul, o Brasil mantém o seu Estatuto do Estrangeiro (Lei $n^{\circ} 6.815$ ) de 1980, remanescente do chamado entulho autoritário do Regime Militar (1964/1985).

No caso argentino, o Plano Pátria Grande regularizou a presença de estrangeiros originários dos Estados Partes do Mercosul e de Estados Associados. No lançamento, o programa foi criticado por não prever o impacto social e econômico. Em 2010, quando foi apresentado o relatório estatístico de implantação, o saldo social mostrou-se significativo, resultante da menor discrepância entre estrangeiros e nacionais argentinos em relação ao acesso a benefícios, bem como redução da vulnerabilidade, na esfera laboral, de migrantes que antes estavam no país sem a devida documentação. Segundo o relatório, "em quatro anos, a Argentina regularizou a situação e emitiu documentos para 423.697 estrangeiros residentes, entre eles 248.144 paraguaios, 104.984 bolivianos, 10.785 uruguaios, 5.349 chilenos e 4.603 brasileiros” (MINTER, 2010, p. 42).

Apesar da repercussão favorável do Plano Pátria Grande junto a organismos internacionais e grupos de defesa dos migrantes, o programa não obteve equivalência nos parceiros do Mercosul. Brasil e Paraguai, que, desde a última década do século XX, enfrentam agravamento de questões relativas aos migrantes, não instituíram ações para regularizar sua presença, como determinaram os Acordos de 2002.

Ainda assim, é inegável que, a partir daqueles acordos regionais, o Mercosul abriu um processo político que levou a decisões notáveis no debate sobre migrações, no lapso de tempo entre sua adoção e início de vigência, em 2009. Já em novembro de 2003, foi criado o Fórum Especializado Migratório (FEM), durante a XIV Reunião dos Ministros do Interior do Mercosul, em Montevidéu. O novo organismo assumiu o objetivo de formular propostas para harmonizar o quadro normativo dos Estados Partes a Associados acerca das migrações. Suas diretrizes foram definidas em maio de 2004, na
Declaração de Santiago sobre Princípios Migratórios, com base no reconhecimento de que o Mercosul deve ter uma política migratória conjunta, fundada no respeito aos direitos humanos e inserida nas relações internacionais. ${ }^{5}$

Uma preocupação presente na Declaração de Santiago sobre Princípios Migratórios foi com a prevenção e o combate ao tráfico internacional de pessoas em suas diversas modalidades: as redes promotoras de trânsito clandestino de migrantes, o aliciamento de trabalhadores, o tráfico individual ou grupal de mulheres e crianças. ${ }^{6}$ Em novembro de 2005, a Declaração de Montevidéu contra o Tráfico de Pessoas regulou a cooperação policial para coibir esses crimes.

A convergência dessas ações apontou para a necessidade de uma legislação que identifique direitos acessíveis a todos os nacionais dos Estados Membros do Mercosul. Desse modo, em dezembro de 2010, o Conselho do Mercado Comum deu um passo na construção de um sistema regional, ao aprovar, em sua Decisão $\mathrm{n}^{\circ}$ 64, o Plano de Ação para um Estatuto da Cidadania do Mercosul. De acordo com o documento, o Estatuto deve se constituir de um conjunto de direitos fundamentais e benefícios disponíveis em igualdade aos nacionais mercosulinos. Um de seus princípios é a liberdade de circulação, fixação, trabalho e exercício de direitos no interior do espaço comunitário.

A agenda do Plano de Ação para um Estatuto da Cidadania do Mercosul, conforme seu projeto, envolve praticamente todos os Ministérios e áreas de governo dos Estados Partes.

5 MERCOSUL. Declaração de Santiago sobre Princípios Migratórios. Disponivel em: http://www.acnur.org/t3/fileadmin/Documentos/BDL/2013/9083.pdf?view=1 Acesso em 25.10.2014.

${ }^{6}$ MERCOSUL. Acordo contra o Tráfico Ilícito de Migrantes entre os Estados Partes do Mercosul, Bolívia e Chile. Disponível em: http://www2.camara.leg.br/atividade-legislativa/comissoes/comissoes-mistas/cpcms/acordosmercosul/Anexo\%20Dec.\%20Leg.\%20568\%202010\%20 Acordo\%20Trafico \%20Ilicito\%20de\%20Imigrantes\%20 Mercosul\%20Chile\%20Bolivia.pdf Acesso em 25.10.2014. Sobre o tema, cf. CASTRO, Mary Garcia. Migrações Internacionais e Direitos Humanos. Por um novo paradigma social internacional. Ecos do Brasil. Global Comission on International Migration (GCIM). Regional Hearing for the Américas. Cidade do México, Maio, 2005. 
No entanto, transcorridos mais de cinco anos desde o seu lançamento, pouco se avançou. A proposta de cidadania regional parece refletir, nos obstáculos que encontra, os percalços do Mercosul para alavancar a integração comercial e econômica, razão primeira de sua existência, vale lembrar. Isso talvez ajude a explicar o diferente comprometimento e as distintas velocidades na implementação dos princípios acordados nos tratados multilaterais do bloco, em relação aos trabalhadores migrantes. $\mathrm{O}$ que, por sua vez, implica a continuidade de políticas públicas profundamente desiguais entre os Estados Partes do Mercosul, no tratamento das migrações regionais.

\section{NORMAS MIGRATÓRIAS E INTE- GRAÇÃO REGIONAL SUL-AMERI- CANA}

O desenvolvimento de políticas migratórias na América do Sul conta, na atualidade, com arcabouços normativos instituídos em cada um dos blocos de integração, o Mercosul e a Comunidade Andina de Nações. Embora haja diferenças substantivas entre os países sul-americanos no tratamento e implementação de políticas internas para migrantes e as migrações, a admissão de diretrizes comuns determina importante avanço. E, se há dificul-

$\because$ dades de efetivar regras de acesso de trabalhaN dores migrantes e seus dependentes a direitos, î é certo que se constituíram, nos últimos anos, $\therefore$ processos de acompanhamento por setores orgे ganizados das sociedades.

될 A realização da $1^{\text {a }}$ Conferência Sul-A\& mericana de Migrações (CSM), em Buenos oे Aires (1999), contribuiu para criar um am-

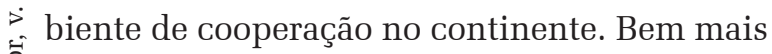
que uma conferência, a CSM é um processo de concertação que se reúne periodicamente, desde aquele primeiro encontro, para debater e deliberar sobre questões pertinentes. Suas reuniões, secretariadas pela Organização Internacional das Migrações, com participação dos doze países da região, proporcionam um foro em perspectiva de governança migratória continental. Entre suas decisões, destacam-se o Plano Sul-Americano de Desenvolvimento Humano das Migrações e a Declaração de Princípios Migratórios e Lineamentos Gerais, firmados na $10^{a}$ CSM, em Cochabamba, Bolívia.

O artigo $1^{\circ}$ da Declaração de Princípios Migratórios e Lineamentos Gerais reconhece a todo nacional sul-americano o direito de migrar, não migrar e retornar de forma livre, informada e segura sem criminalizar os deslocamentos. ${ }^{7}$ Posiciona o migrante no centro das elaborações normativas e dos programas de governo, ao assumir que, na América do Sul, não se considerará a nenhum ser humano como ilegal por estar em situação migratória irregular. No que respeita diretamente aos dois blocos regionais, seu Artigo $11^{\circ}$ dispõe que a mobilidade com direitos de todas as pessoas migrantes constitui parte substancial dos processos de integração. Nessas instruções, Mercosul e CAN projetam, juntos, um futuro de proteção aos migrantes.

Tais avanços resultam de pressões das sociedades sul-americanas e são acompanhados de permanências institucionais na ordem doméstica dos Estados mercosulinos e andinos. Nesse sentido, importa mencionar que se mantêm em vigor acepções discriminatórias do trabalhador migrante. A ideologia de segurança nacional, definidora da norma nos regimes autoritários das décadas de 1960/1980, continua a instruir leis e procedimentos. É o caso do Estatuto do Estrangeiro, principal diploma brasileiro sobre a matéria, portador de visão policial das migrações. Controle e vigilância são seus objetivos, não a regularização do migrante e a facilitação do acesso a direitos. Mesmo a Argentina, que implementou ações em larga escala em prol dos migrantes regionais, enfrenta exclusão e desigualdade entre nacionais e estrangeiros.

7 CONFERENCIA SUL-AMERICANA DE MIGRAÇÕES. Declaração de Princípios Migratórios e Lineamentos Gerais. Cochabamba, 2010. Disponível em: http://csm-osumi. org/Archivos/DocCSM/3\%20Declaraci\%C3\%B3n\%20principios\%20POR.pdf. Último acesso em 25.08.2015. 
É improvável a concretização, em curto prazo, da ideia de fronteiras abertas, inaugurada pelo libertador Simon Bolívar. Ao menos enquanto os blocos de integração regional não estabelecerem vínculo irrefutável entre o fenômeno migratório e os direitos advindos da cidadania. Essa formulação foi incluída no Plano de Ação para um Estatuto da Cidadania do Mercosul (2010). Desde então, pouco se encaminhou. Na Comunidade Andina de Nações, a proposta de cidadania comunitária é ainda mais embrionária. Elemento promissor nos dois processos é o balizamento jurídico em premissas de respeito aos direitos humanos dos migrantes, da liberdade de circulação e radicação à igualdade de acesso ao trabalho e a direitos sociais. É um direcionamento pautado por demandas democráticas, enlace regulatório consistente para o futuro das sociedades sul-americanas. O tempo para a integração será o da abertura das portas do continente.

Recebido para publicação em 15 de outubro de 2015 Aceito em 21 de novembro de 2015

\section{REFERÊNCIAS}

ARGENTINA. MINISTERIODEL INTERIOR. Patria Grande. Programa Nacional 4 de Normalización Documentaria Migratoria. Direccíon Nacional de Migraciones. Informe Estadistico. Agosto de 2010, p. 42. Disponível em: < http:// www.migraciones.gov.ar/pdf_varios/estadisticas/Patria Grande.pdf>. Acesso em: 20 nov. 2014.

BRASIL. MINISTÉRIO DA PREVIDÊNCIA SOCIAL. Migrações internacionais e a Previdência Social. Brasília: MPS, 2006.

CASTRO, M. G. Migrações Internacionais e Direitos Humanos. Por um novo paradigma social internacional. Ecos do Brasil. Global Comission on International Migration (GCIM). Regional Hearing for the Américas. Cidade do México, maio, 2005.

COMUNIDADE ANDINA DE NAÇÕES. Diez decisiones en materia migratoria objeto del Proyecto OIM-SGCAN. Disponível em: <http://www.oimperu.org/docs/ ANEXOSGCAN.pdf $>$. Acesso em: 16 ago. 2015.

Documentos de la Comunidad Andina. Acta de La $\overline{P a z}$ y Directrices Presidenciales. IV Reunión del Consejo Presidencial Andino, 29-30.11.1990. Disponível em: <http:// www.comunidadandina.org/documentos/actas/act30-11-90. htm >. Acesso em: 01 ago. 2015.

COSTA, L. C. da; CERVI, E. U.; MANDALOZZO, S. S. "Democracia e proteção social: possibilidades e contradições no Mercosul”. In: LUIZ, D. C. (org.). Sociedade
Civil e democracia: expressões contemporâneas. São Paulo: Veras Editora, p. 205-229, 2010.

DOLINGER, J. Direito Internacional Privado (Parte Geral). Rio de Janeiro: Renovar, 2005.

ESTRADA, M. The impact of land policies on international migration: the case of the Brasiguaios. University of Oxford. International Migration Institute. v. 120, 2015. Disponível em: <http://www.imi.ox.ac.uk/publications/ the-impact-of-land-policies-on-international-migrationthe-case-of-the-brasiguaios >. Acesso em: 13 out. 2015.

GENEYRO, R; MUÑOZ, M. "Evolución del tratamiento de la tematica socio laboral. Enumeración y análisis del SGT $\mathrm{n}^{\mathrm{o}}$ 10/GMC Relaciones Laborales, Empleo y Seguridad Social". In: Revista de Direito do Mercosul/Revista de Derecho del Mercosur, $\mathrm{n}^{\circ}$ 5, ano 2, Buenos Aires, p.193204, out. 1998.

HIRST, M. A dimensão política do Mercosul: especificidades nacionais, aspectos institucionais e atores sociais. In: MARTINS, G. d'O. et al. (Orgs.). Integração aberta: um projeto da União Europeia e do Mercosul. Instituto de Estudos Estratégicos e Internacionais, Lisboa, p. 174, 1995.

MANDRILE, M. El Corredor de Remesas Sur-Sur ArgentinaBolivia. Buenos Aires: OIM. Oficina Regional para a América del Sur, 2013. ORGANIZAÇÃO INTERNACIONAL PARA AS
MIGRAÇÕES (OIM). Panorama Migratorio de América del Sur 2012. Buenos Aires: OIM. Oficina Regional para a América del Sur, p. 90, 2012.

SANAHUJA, J. A. Del 'regionalismo abierto' al 'regionalismo post-liberal'. Crisis y cambio en la integración regional en América Latina y el Caribe. In: MARTÍNEZ, L.; PEÑA, L.; VÁZQUEZ, M. (coord.). Anuario de la Integración de América Latina y el Gran Caribe, Buenos Aires, Coordinadora Regional de Investigaciones Económicas y Sociales, $n^{\circ}$ 7, p. 11-54, 2008-2009.

SOARES FILHO, J. Mercosul: surgimento, estrutura, direitos sociais, relação com a Unasul, perspectivas de sua evolução. In: Revista do Centro de Estudos Judiciários, Brasília, Ano XIII, nº 46, p. 21-38, jul./set. 2009. 


\section{¿PUERTAS ABIERTAS?: regional migrations, right and integration in the Andean Community of Nations and the Mersocul}

\author{
José Sacchetta Ramos Mendes
}

In the last decades Mercosur and the Andean Comunity of Nations set important legislations on regional migration and the treatment of migrants. South American regional integration organizations have originally trade objectives and only later added social issues to their goals, among them regional migration. This article presents the normative development conducted in South American integration processes in their search for solutions to the problems of human displacement stemmed from neighboring countries. Despite advances, there remain legal barriers to regularize the status of regional migrants and their access to social and political rights. Main obstacles are the misalignment of internal law towards multilateral agreements and the minor participation of South American societies in decision-making processes. The article also comments the adoption of general principles on regional migration based on respect for the human rights and the route of inclusion of migrants in a broader regional citizenship project.
¿PORTES OUVERTES?: migrations régionales, droit et intégration dans la Communauté Andine des Nations et dans le Mercosur

\author{
José Sacchetta Ramos Mendes
}

$\mathrm{Au}$ cours des dernières décennies, le Mercosur et la Communauté Andine ont défini des législations communautaires concernant les migrations régionales et les migrants. Ces deux entités ont été créées pour atteindre des objectifs d'intégration commerciale auxquels se sont ajoutées, par la suite, des questions sociales. Cet article présente le développement normatif réalisé dans les processus sud-américains d'intégration en vue de solutions pour résoudre la problématique des déplacements humains provenant des pays voisins. Malgré tous ces progrès, il existe toujours des obstacles politiques et juridiques pour régulariser le statut des migrants et leur accès aux droits sociaux. Parmi les raisons évoquées, il y a le manque de standardisation des normes internes des pays par rapport aux accords multilatéraux ainsi que la faible participation des sociétés sud-américaines dans le processus décisionnel. On y commente l'adoption de principes généraux basés sur le respect des droits de l'homme et la manière d'inclure la migration et les migrants dans un projet de citoyenneté régionale.

KEYwords: Migrant. Regional Migration. Citizenship. Mot-CLÉs: Migration régionale. Amérique du Sud. South America. Andean Community of Nations. Communauté Andine des Nations. Mercosur. Mercosur.

José Sacchetta Ramos Mendes - Doutor em História Social. Pós-doutor no Department of History and Civilization do European Institute University (Florença, Itália) e no Departamento de Filosofia e Teoria do Direito da Faculdade de Direito da USP. Professor do Instituto de Humanidades, Artes e Ciências Professor Milton Santos (IHAC/UFBA) e professor permanente do Programa de Pós-Graduação em Direito da Universidade Federal da Bahia. Como pesquisador, trabalha com História e Direito nos temas de imigração, etnicidade, relações internacionais e estudos luso-afro-brasileiros. É pesquisador do Laboratório de Estudos sobre Etnicidade, Racismo e Discriminação (LEER/USP) e do Laboratório de Análise Política Mundial (Labmundo/UFBA). Publicações recentes: Política de cotas para ingresso em instituições federais de ensino superior: um estudo interdisciplinar da Lei n. 12.711/2012. Diálogo (UNILASALLE), v. 1, p. 73-99, 2015; Direito e ciências humanas na pesquisa universitária brasileira. Direito e Sociedade (Catanduva), v. 6, p. 87-102, 2011. Lei e etnicidade no Brasil: entre a lusofobia e o favorecimento jurídico dos portugueses. Ciência e Cultura, v. n. 62, p. 50-53, 2009 